\title{
Capítulo III \\ La gestión comunitaria del agua, garantía para su acceso, control, distribución y uso eficiente en las comunidades indígenas
}

\author{
José Manuel Perugachi Cachimuel
}

Charles Cachipuendo Ulcuango

\section{SciELO Books / SciELO Livros / SciELO Libros}

PERUGACHI CACHIMUEL, J. M., and CACHIPUENDO ULCUANGO, C. La gestión comunitaria del agua, garantía para su acceso, control, distribución y uso eficiente en las comunidades indígenas. In: La lucha por el agua: Gestión Comunitaria del Proyecto de Agua Potable Pesillo-Imbabura [online]. Quito: Editorial Abya-Yala, 2020, pp. 119-162. ISBN: 978-9978-10-473-6. http://doi.org/10.7476/9789978105764.0004.

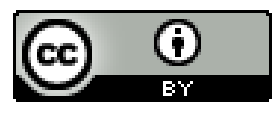

All the contents of this work, except where otherwise noted, is licensed under a Creative Commons Attribution 4.0 International license.

Todo o conteúdo deste trabalho, exceto quando houver ressalva, é publicado sob a licença Creative Commons Atribição 4.0.

Todo el contenido de esta obra, excepto donde se indique lo contrario, está bajo licencia de la licencia Creative Commons Reconocimento 4.0. 


\section{Capítulo III La gestión comunitaria del agua, garantía para su acceso, control, distribución y uso eficiente en las comunidades indígenas}

El ejercicio pleno del derecho humano al acceso al agua enfrenta limitaciones políticas, técnicas y organizativas, especialmente en las zonas rurales y periurbanos (Foro de los Recursos Hídricos, 2015). Por eso la mayoría de las soluciones para acceder al agua en las comunidades son iniciativas locales que en base a su constancia y con el apoyo de instituciones públicas y privadas construyen sistemas de agua entuba$\mathrm{da}$, cuyas fuentes pueden o no encontrarse en sus territorios.

Los proyectos en territorios comunitarios se construyen de forma comunitaria, con la participación de los potenciales beneficiarios, inician generalmente con mingas de ideas que solucionen sus problemas, para que estos sean factibles las organizaciones buscan el acompañamiento técnico de instituciones que compartan sus visiones e intereses. Los proyectos son presentados a las instituciones representantes del Estado según sus competencias para que sean evaluadas su factibilidad, pero muchas veces estas instituciones tienen limitaciones técnicas y económicas, por lo que las comunidades también invierten recursos económicos contratando profesionales para realizar estudios técnicos preliminares y/o definitivos, como aconteció con las comunidades del Consejo de Juntas. 


\section{Figura 31}

Proceso de solución al problema de falta de agua desde el enfoque de la gestión comunitaria del agua

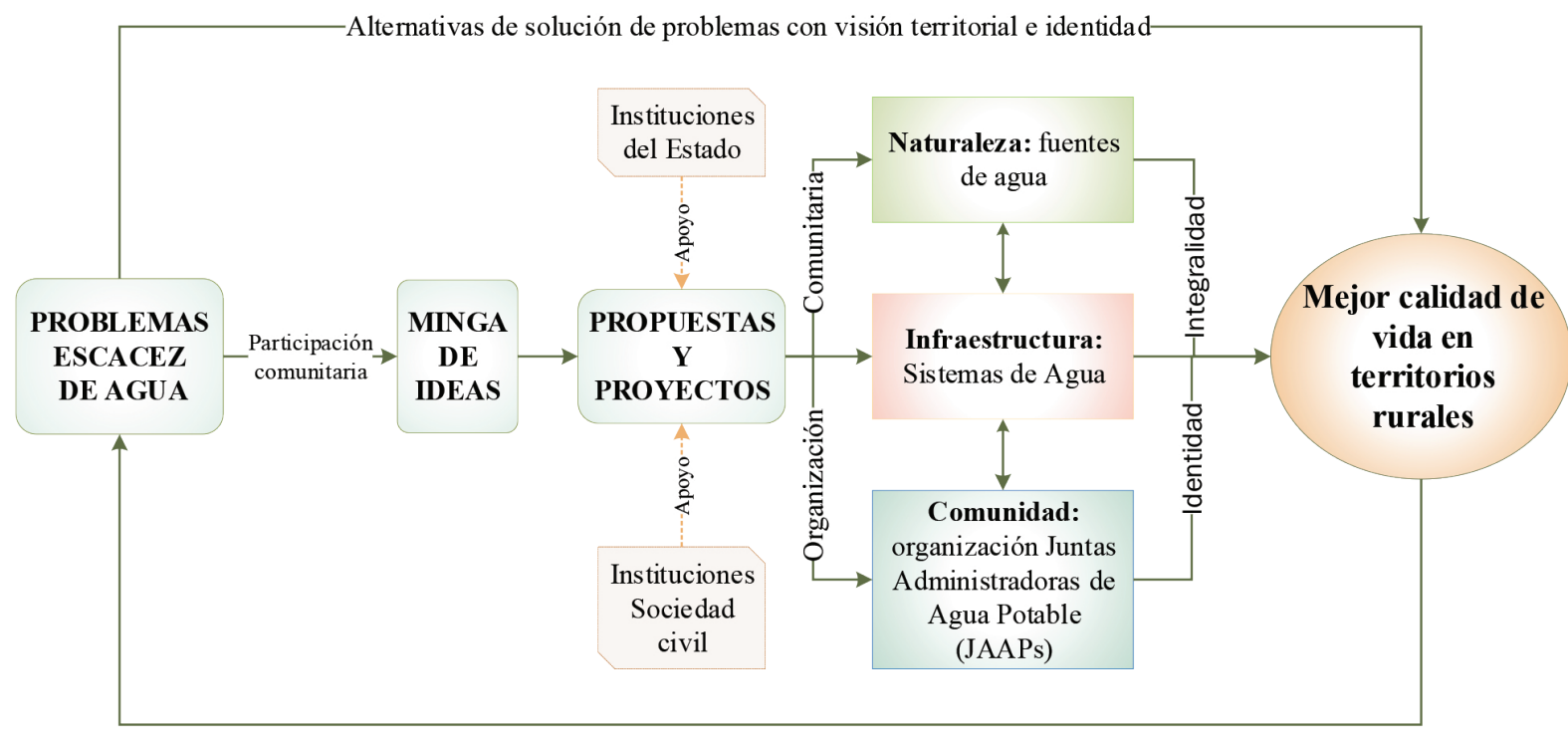


Según Cachipuendo (2017), cuando se analiza un proyecto, las comunidades no solo piensan en la infraestructura física, sino también de dónde viene el agua y cómo la organización va manejarla, así, se consideran a un sistema con una visión de integralidad donde existen relaciones entre la naturaleza, la comunidad y la infraestructura física como tal, razón por la cual las necesidades de abastecimiento de agua obliga a las comunidades proponer proyectos que según sus dinámicas solucionen sus problemas de forma sostenible en el tiempo (Figura 31).

En la fase de ejecución de proyectos, los futuros usuarios también aportan dinero, colaboran con materiales y participan en mingas. Cuando los sistemas de agua están en operación participan en la gestión, administración, vigilancia, control social y veedurías comunitarias de tal forma que se garantice el acceso al agua a todos sus comuneros. Los grupos vulnerables adultos mayores y/o madres solteras, personas con capacidades especiales se benefician con tarifas especiales; es decir, tienen derechos y obligaciones a lo largo de sus vidas, de esta manera se practica la solidaridad, principio fundamental de la gestión comunitaria del agua.

Una de las actividades importantes del Consejo de Juntas fue que involucró en el proyecto de consecución del PPI planes de gestión ambiental en las zonas de captación del agua. Por lo tanto, existe una intervención social en el territorio a través de mingas para minimizar los impactos de las sequias. Así, el agua, como un elemento dinámico circula a través del ciclo hidro-social, mediante una compleja red de infraestructura que capta el agua luego es conducida y distribuida en los diferentes sectores beneficiarios, es decir, para acceder al agua se requiere una relación entre la naturaleza y la acción social (Perreault, 2015).

La comunidad contribuye a mejorar sus condiciones de vida cuando acceden al agua, y últimamente también son encargadas de la disposición final de las aguas residuales "saneamiento", acciones que son gestionadas y manejadas por las organizaciones basadas en 
122

la participación desde su construcción, por lo que la comunidad se encuentra comprometida en su funcionamiento y administración (Bastidas \& García, 2002).

Las prácticas implementadas por las organizaciones comunitarias para acceder, controlar, distribuir y usar el agua se fundamentan en la participación de todo/as, en la capacidad de diálogo al interno y al externo de la organización, manteniendo una visión territorial y de interculturalidad. En este sentido, sí, la gestión comunitaria del agua garantiza el acceso al agua a todos/as, también está la organización en la capacidad de ejercer sus derechos, mantener una visión territorial, construcción de un tejido social, en la puesta en práctica principios de gobernanza y gobernabilidad con identidad según las realidades locales.

\section{El derecho al agua y la organización comunitaria}

A finales del 2015 fueron aprobados los Objetivos de Desarrollo Sostenible por parte de las Naciones Unidas, mismos que cada país que firma el acuerdo debe cumplirlos hasta el año 2030. El objetivo 6 agua limpia y saneamiento, pretende "garantizar la disponibilidad de agua y su gestión sostenible y el saneamiento para todos", pese de existir estos postulados a nivel global no necesariamente garantizan el acceso universal al agua, y no existe una organización internacional que afronte los desafíos que supone la gestión eficiente del agua y del medio ambiente (Hortelano Villanueva, \& Hidalgo García, 2016).

El Consejo de Juntas para exigir al Estado el financiamiento del PPI se respalda en la Constitución del 2008 que plantea algunos postulados para garantizar el derecho al agua. Así, en el artículo 3, se estableció como el primer deber primordial del Estado: "Garantizar sin discriminación alguna el efectivo goce de los derechos establecidos en la Constitución y en los instrumentos internacionales, en particular la educación, la salud, la alimentación, la seguridad social y el agua para sus habitantes". Mientras que el artículo 12 determina que "el derecho humano al agua es fundamental e irrenunciable. El 
agua constituye patrimonio nacional estratégico de uso público, inalienable, imprescriptible, inembargable y esencial para la vida". Para la gestión y manejo del agua en el artículo 411 manifiesta que:

El Estado garantizará la conservación, recuperación y manejo integral de los recursos hídricos, cuencas hidrográficas y caudales ecológicos asociados al ciclo hidrológico. Se regulará toda actividad que pueda afectar la calidad y cantidad de agua, y el equilibrio de los ecosistemas, en especial en las fuentes y zonas de recarga de agua.

Las comunidades andinas para acceder al agua implementan sistemas de gestión y manejo del agua según sus dinámicas socio culturales y ambientales, y por sus constantes reclamos logran que en la Constitución del 2008 se reconozca sus formas de gestión, así en el artículo 318 manifiesta:

El agua es patrimonio nacional estratégico de uso público, dominio inalienable e imprescriptible del Estado, y constituye un elemento vital para la naturaleza y para la existencia de los seres humanos.... La gestión del agua será exclusivamente pública o comunitaria. El servicio público de saneamiento, el abastecimiento de agua potable y el riego serán prestados únicamente por personas jurídicas estatales o comunitarias. (Constitución, 2008)

Para operativizar los postulados de la Constitución, en el Código Orgánico de Organización Territorial, Autonomía y Descentralización (COOTAD), la competencia para dotar de agua segura recae a los gobiernos municipales como lo manifiesta el artículo 137:

Los gobiernos autónomos descentralizados municipales planificarán y operarán la gestión integral del servicio público de agua potable en sus respectivos territorios, y coordinarán con los gobiernos autónomos descentralizados regional y provincial el mantenimiento de las cuencas hidrográficas que proveen el agua para consumo humano.

Pero desde décadas pasadas, dada la debilidad del Estado y los gobiernos municipales, no atiende las necesidades de las comunidades andinas y en particular a las filiales del Consejo de Juntas, por lo que los comuneros se organizan y generan alternativas que al menos permiten 
124

acceder al agua entubada. Entonces se debe entender a las organizaciones comunitarias como entidades que buscan resolver problemas que afectan a su población, desarrollando iniciativas en constante relación con su espacio territorial. Esto exige que la participación sea permanente y exista una articulación con los diversos actores bajo lazos de confianza, reciprocidad, cooperación y armonía, principios fundamentales del Buen Vivir y aplicados en la gestión comunitaria del agua.

Las JAAP además de ser entidades constituidas jurídicamente y en algunos casos únicamente legítimas, son organizaciones comunitarias que buscan dotar de agua a todo/as los miembros de la comunidad, enfrentando así, la marginación de las entidades del Estado quienes tienen estas competencias. Estos procesos organizativos a nivel de comunidad trascienden en las instituciones públicas cuando el problema no es únicamente en una comunidad, sino que se extiende a territorios más amplios como el caso del PPI, por lo que es necesario la existencia de procesos organizativos intracomunitarios como intercomunitarios, este tipo de organización tiene mayor poder de reclamar sus derechos, y poder impulsar y exigir al Estado la concreción de proyectos regionales que doten de agua a sus pobladores.

La participación de los miembros de la organización exige al Estado cumplir con sus roles permitiendo plasmar la ejecución de los proyectos como es el caso del PPI, donde se lo realizó de forma conjunta. Así, las organizaciones comunitarias se dan a conocer ante las diferentes instituciones como actores fundamentales que tienen intereses y demandas comunes, convirtiendo sus formas de actuación comunitaria en procesos con cierta autonomía y articulan con otros actores sociales y de las instituciones públicas, en búsqueda del bienestar de su población (Bastidas \& García, 2002).

En la década de 1990 era difícil pensar en una articulación inter cantonal e interprovincial de las organizaciones comunitarias. Los únicos ejemplos hasta ese entonces fueron el de las comunidades y unión de comunidades indígenas agrupados en la Federación Indígena y Campesina de Imbabura, cumpliendo importantes jornadas de lucha por los derechos colectivos y el acceso a la tierra. 
$\mathrm{Al}$ ser el agua un elemento que no reconoce fronteras, la articulación entre las JAAP comunitarias se convierte en un sistema organizativo que genera poder, en muchas ocasiones sirve como bandera de lucha del movimiento indígena y sectores rurales, enfocándose principalmente en reclamar el derecho de acceder al agua. En este proceso prevalece la participación y articulación entre los actores mediante el diálogo, los lazos de confianza, la reciprocidad, la armonía y la cooperación en sus reclamos; así, a partir de las organizaciones comunitarias de base se construyó un símbolo social llamado Consejo de Juntas que impulsó la construcción del Proyecto de Agua Potable Pesillo-Imbabura.

En función de objetivos comunes y principios comunitarios, la unidad de las organizaciones comunitarias ha permitido que los límites geográficos comunales, parroquiales, cantonales y provinciales no tengan importancia en la consecución de acuerdos. El PPI es resultado de procesos que se han construido a lo largo de años, logrando unir y reunir miles de personas de diferentes comunidades y centros poblados, dejando de un lado las visiones políticas o intereses personales, un proceso de reconocimiento de sus problemas y potencialidades, que bien se puede llamar interculturalidad, porque las diferentes instituciones públicas, privadas y de la sociedad civil se involucran y aportan en la ejecución de proyecto (Figura 32).

Los intereses y realidades entre los beneficiarios del proyecto: juntas comunitarias, regionales y empresa pública, midió la capacidad de negociación y llegar a acuerdos para lograr la ejecución de la infraestructura, quedando aun el análisis del modelo de gestión y manejo del sistema. Pese a los problemas y diferencias, así como los disensos en el camino transitado desde los inicios del proyecto, a decir de Bastidas y García (2002), lo que mantiene a las organizaciones unidas es el propósito de acceder al agua sin perder el horizonte ni las esperanzas. 


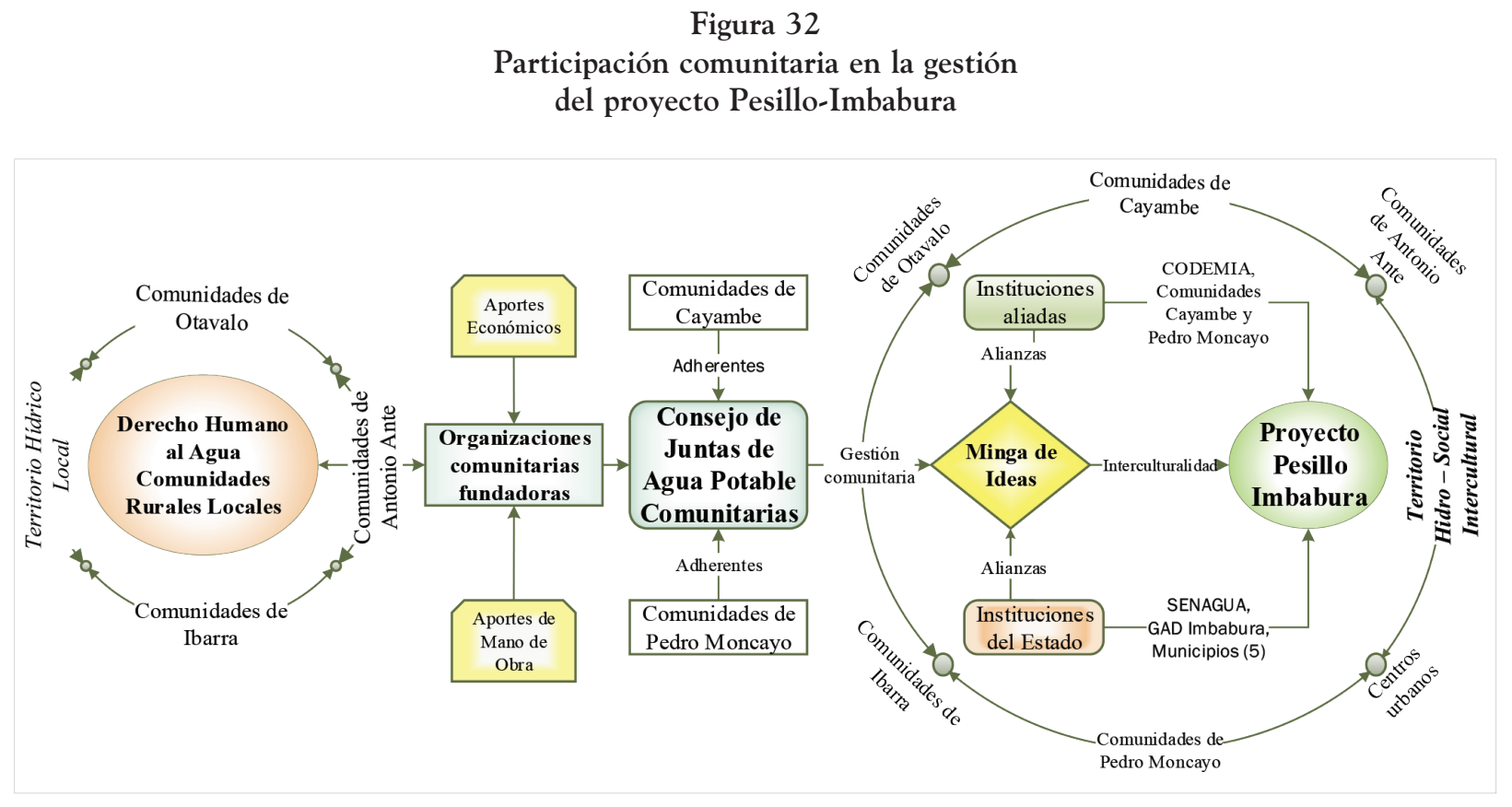


La participación comunitaria en las asambleas y reuniones de trabajo sirven para evidenciar las realidades en las diferentes comunidades y JAAP. Los problemas comunes en vez de distanciarlos los han unido, prácticas de diálogo que permiten llegar a consensos superando las diferencias entre comunidades y pueblos indígenas: Kayambis, Karankis, Otavalos, Natabuelas y pueblo mestizo. Estos espacios de diálogo enfocados en la ejecución del proyecto se convierten en escenarios que fomentan la interculturalidad y los principios de acción colectiva y comunitaria.

Los beneficiarios del PPI se encuentran agrupados en diversas organizaciones de gestión y manejo de los sistemas de agua de consumo humano: 1) empresas públicas, 2) organizaciones colectivas y 3) organizaciones comunitarias. Cada una de estas organizaciones se encuentra dentro de la Ley de Recursos Hídricos, y tienen sus propias características. Sin embargo, a nivel nacional se puede identificar un cuarto tipo de organización, la privada como es el caso de Interaguas de Guayaquil (Figura 33).

Desde la legalidad, las organizaciones colectivas y comunitarias son reconocidas como Juntas de Administradoras de Agua, pero existen diferencias entre estas por el tipo de gestión y manejo del sistema.

Las organizaciones comunitarias de gestión y manejo de agua de consumo humano, se estructuran mediante una JAAP o a través del gobierno comunitario; sin embargo, cualesquiera que sean estas, tienen como característica que sus usuarios viven en un sistema comunitario, en donde se practican principios y valores de la cosmovisión indígena andina como: la toma de decisiones comunitarias en "asambleas", aportes de mano de obra mediante las "mingas", aportes económicos denominados "tarifas" y relación de armonía con la naturaleza (cuidado de las fuentes de agua). Existe un proceso democrático para elegir a sus dignatarios (dirigentes), y la exigencia de rendición de cuentas de gestión y administración financiera a los dignatarios de turno son prácticas generalizadas en este tipo de organizaciones. 


\section{Figura 33}

Tipo de organizaciones que gestionan y manejan el agua de consumo humano a nivel comunitaria y colectiva

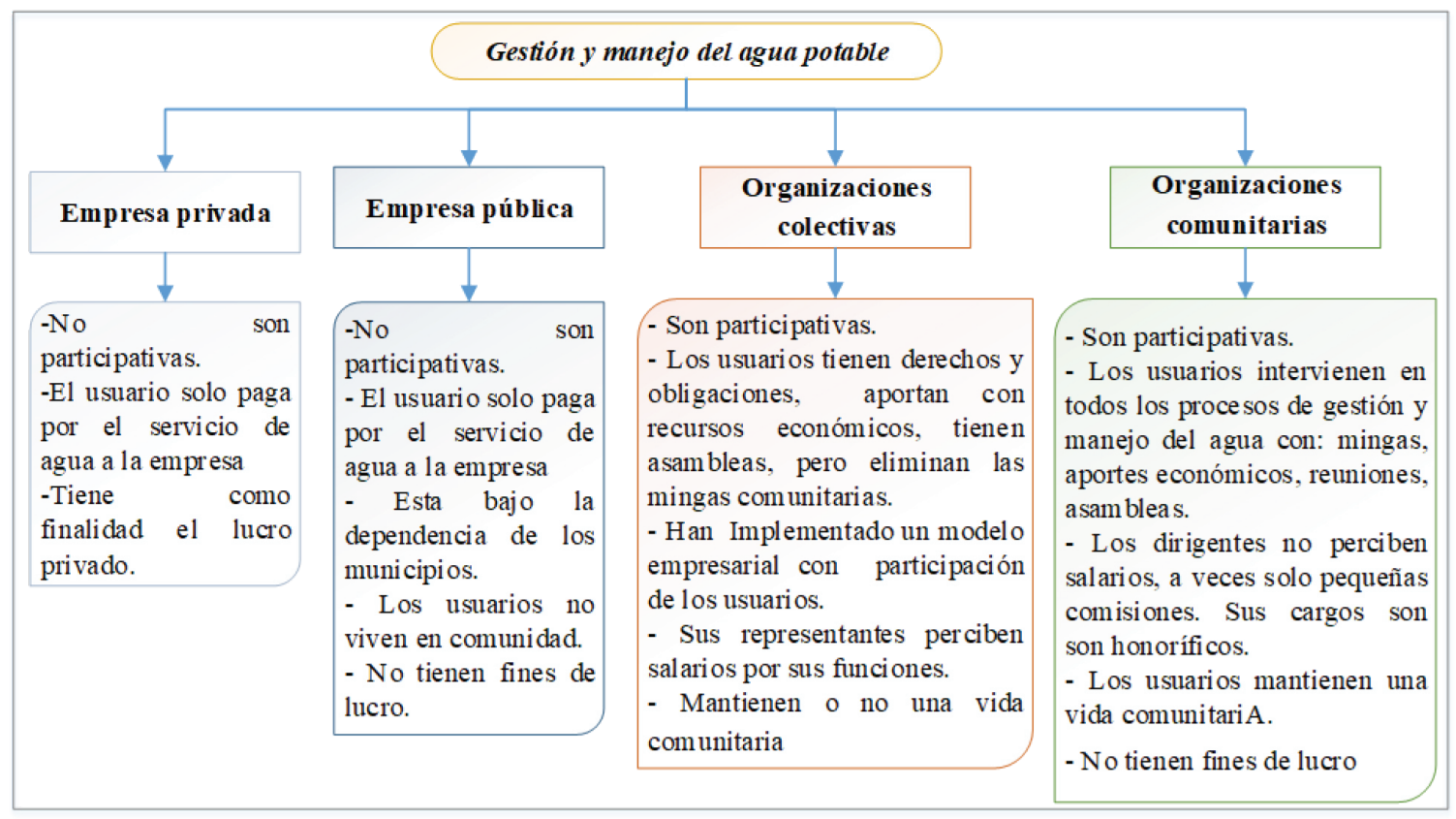


Las organizaciones colectivas, este tipo de organizaciones se encuentran en las cabeceras parroquiales (centros poblados), su gestión y manejo se lo realiza a través de la JAAP, cuya visión es como una empresa de prestación del servicio, se practica la elección de sus representantes de manera democrática, se realizan asambleas para la rendición de cuentas, pero tienen trabajadores por lo que las mingas comunitarias no son usuales.

Las empresas públicas, generalmente prestan el servicio a las cabeceras cantonales y son adscritas a los Gobiernos Autónomos Descentralizados Municipales, no existe participación de los usuarios en la gestión y/o manejo del agua, sus representantes son delegados por los gobiernos municipales de turno, y mantienen una representación de los usuarios como veedores.

Las empresas privadas, pese que en la Constitución prohíbe la privatización del agua, existe en el país una delegación del GAD Municipal a la empresa privada para que esta se encargue de la gestión y manejo del agua, este tipo de organización busca la rentabilidad financiera, lo que provoca que la dotación de agua se realice únicamente a sectores que les va a ser rentables.

A modo de reflexión podemos decir que las organizaciones comunitarias (comunidades y JAAP) son el motor del movimiento social en la lucha por el derecho al agua. Estas sostienen al Consejo de Coordinación de Juntas Administradoras de Agua Potable del Proyecto Regional Pesillo-Imbabura que se ha convertido en una organización con incidencia regional y nacional, articulándose además con otras organizaciones que persiguen los mismos objetivos. Es claro que, sin organizaciones comunitarias de base, la lucha por el agua sería débil y desarticulada, siendo a lo mucho como en décadas pasadas reclamos locales, coyunturales y de contenidos particulares. De ahí la importancia de las JAAP regionales, como organizaciones con una visión comunitaria e intercultural que logra la concreción del $\mathrm{PPI}^{29}$ (Figura 34).

29 Como se indicó en la presentación, los trabajos en estos momentos están estancados. Si se retoman los trabajos y se concluyen las obras, será un triunfo de las comunidades y JAAP organizadas. 
Figura 34

Asociatividad de organizaciones de base para conformar una organización de segundo nivel o grado

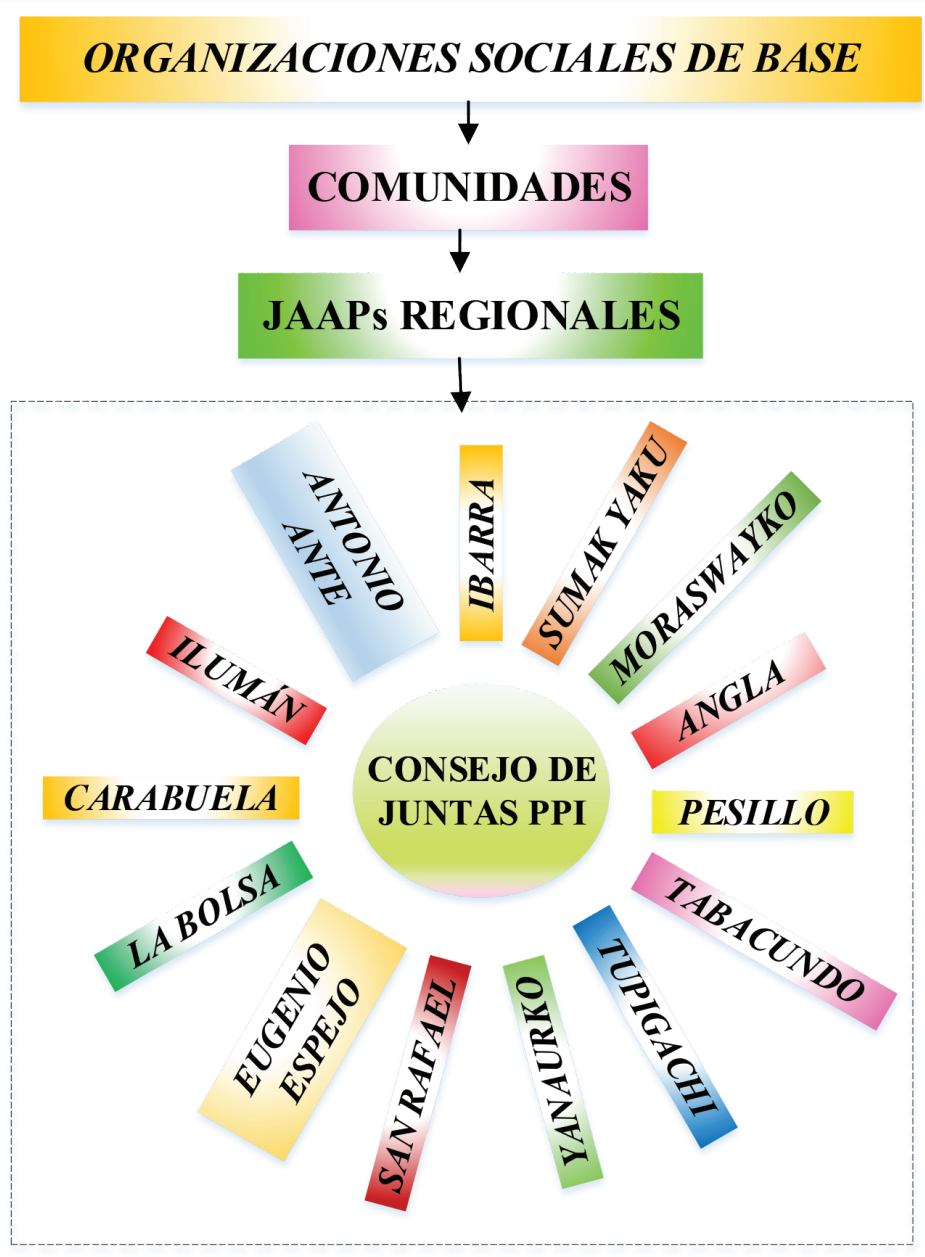




\section{La cultura organizacional comunitaria para la gestión y manejo del agua}

El acceso al agua es esencial para la concreción de los derechos humanos, es parte del derecho a la vida, debiendo los Estados invertir y proporcionar los recursos económicos necesarios para dotar del servicio del agua o la delegación a las organizaciones comunitarias. En la actualidad, a partir el decreto del 2017 se reconoce que las organizaciones comunitarias pueden gestionar y manejar el sistema de agua potable en los territorios. Cuando esto no sucede las comunidades se organizan para exigir su cumplimiento, siendo la capacidad organizativa el único recurso con el que cuentan las comunidades.

Las limitaciones económicas, la falta de voluntad de los gobiernos locales y las autoridades seccionales han hecho que, los sectores marginados deban organizarse, siendo la principal estrategia y herramienta del que disponen para hacerse escuchar. La organización en el marco de la solidaridad y la unidad, de intereses y demandas comunes han llevado a actuar de manera colectiva (Bastidas \& García, 2002). La organización tradicionalmente ejerce sus acciones en la Llakta $^{30}$ o comunidad, pero en proyectos de amplia cobertura son organizaciones donde es difícil el homogenizar las acciones de gestión y manejo por un sentimiento de apropiación, esto en ocasiones provocan conflictos.

Esta forma de organización comunitaria sirvió para defenderse de los abusos de los colonizadores ibéricos, de los hacendados y otras formas de explotación en los siglos XIX y XX. En la actualidad, es un nicho de poder local que articula sus acciones para dar alternativas ante un sistema político y económico capitalista predominante. Además de ser espacios de resistencia, se reproduce la matriz cultural y reivindicaciones para reclamar sus derechos.

30 Es un espacio territorial donde habitan hombres y mujeres emparentados entre sí, la comunidad propiamente. 
132

Las comunidades fueron el epicentro de las iniciativas para presionar a las autoridades e instituciones; en el caso del agua, en las décadas de 1970, 1980 y 1990 las luchas fueron locales y coyunturales, donde cada comunidad en base a sus problemas de acceso al elemento vital gestan proyectos que modifiquen estas realidades, volviéndoles comunidades resilientes, es decir, que tienen capacidades de adaptación, social, política, ambiental y económica y continuar con su vida basada en alcanzar el Sumak Kawsay. ${ }^{31}$

Con la creación de la Ley de agua de 1972, para que una organización colectiva y/o comunitaria pueda gestionar y manejar el agua, se conforman las JAAP de forma paralela al cabildo comunitario (comunidad), para que estas legalmente puedan prestar el servicio de dotación de agua de consumo humano. También se crean las JAAP regionales mediante la unión de varias comunidades, desencadenándose un lento pero sostenido proceso de organización que tiene como fin la gestión y manejo comunitario del agua. Sin embargo, dentro de ellas y en el ejercicio de la gestión del agua se desarrollaron valores y principios que rigen en las comunidades y guía y norman el accionar de la convivencia entre las personas en sus territorios (Sánchez-Parga, 2007). Eso sí, en muchas partes se generan conflictos, intereses y superposiciones de poder entre los directivos de la JAAP y el cabildo de la comunidad, que con el tiempo y considerando que son los mismos comuneros buscan alternativas de coordinación de acciones en la gestión del agua potable.

La apertura jurídica de la Ley de Recursos Hídricos emitida en el 2014, se evidencia un avance en la conceptualización de gestión y manejo comunitario que pretende que los conocimientos occidentales se articulen con las experiencias locales de las comunidades andinas, incorporando la cultura como elemento esencial. Así, las JAAP implementan formas propias de gobernanza y gobernabilidad

31 Buen vivir o la vida en armonía, principio y filosofía de vida de los pueblos indígenas. En la actualidad es un derecho ambiental y ecológico, y principio del régimen de desarrollo social y políticos del país. 
del agua, entrelazando las dinámicas sociopolíticas y ambientales del territorio y la normativa legal del Estado.

Cuando el abastecimiento del agua en las comunidades sufre una disminución en la disponibilidad de agua por el cambio climático, las inequidades políticas y conflictos de poder entre lo urbano y lo rural, las menos favorecidas para enfrentar estas realidades son las comunidades. Así, las comunidades y sus organizaciones como las JAAP son relegadas de la acción de la política en el destino de la inversión pública; ante esta situación optan por acercarse y realizar alianzas intercomunitarias o inter-JAAP para hacer fuerza social y ser atendidos; en palabras de Sánchez-Parga (2007) "cuando una organización se fortalece y se amplía más allá de las comunidades moderniza sus reivindicaciones", equilibrando el poder de diálogo y negociación.

El Consejo de Coordinación de Juntas Administradoras de Agua Potable del Proyecto Regional Pesillo-Imbabura, no es solo un sistema de modernización en forma de la ampliación geográfica y cobertura social para una reivindicación específica, es un modelo de organización que han adoptado las comunidades indígenas y JAAP para reclamar su derecho al agua ante el Estado, mejorando sus capacidades técnicas, económicas y de poder, "el hombre andino nunca es más frágil que cuando está solo, y más fuerte cuando está incorporado al grupo" (Sánchez-Parga, 2016).

\section{Capacidad de la organización comunitaria para la gestión y manejo del agua}

En los Andes ecuatorianos, las organizaciones comunitarias que realizan procesos de gestión y manejo del agua tienen amplia trayectoria. En el caso del territorio del PPI, la mayoría de las organizaciones - comunidades y las JAAP - tienen debilidades principalmente por falta de recursos económicos para remunerar a sus propios técnicos y no depender de instituciones externas para enfrentar problemas técnicos en la infraestructura del sistema. El Foro de los 
134

Recursos Hídricos (2013) señala algunas limitaciones, siendo estos: la escasez de recursos económicos, la conflictividad comunitaria, limitadas capacidades técnicas para el manejo de los sistemas, dificultad para la renovación de líderes o dirigentes, dificultades jurídicas legales, dificultad en el control y vigilancia de la calidad del agua e inequidades de género.

Los problemas más comunes que enfrentan la mayoría de las organizaciones son las condiciones deterioradas de la infraestructura y disminución de caudales o ausencia de fuentes de agua, la disputa de gestión entre las organizaciones públicas (EMAP) y la cambiante estructura gubernamental que es responsable en la operativización de la política pública (Foro de los Recursos Hídricos, 2015). Estos aspectos endógenos y exógenos a las organizaciones afectan la capacidad de gestión y de manejo del agua (Figura 35).

\section{Figura 35}

Factores endógenos y exógenos que debilitan a la organización comunitaria en la gestión y manejo del agua

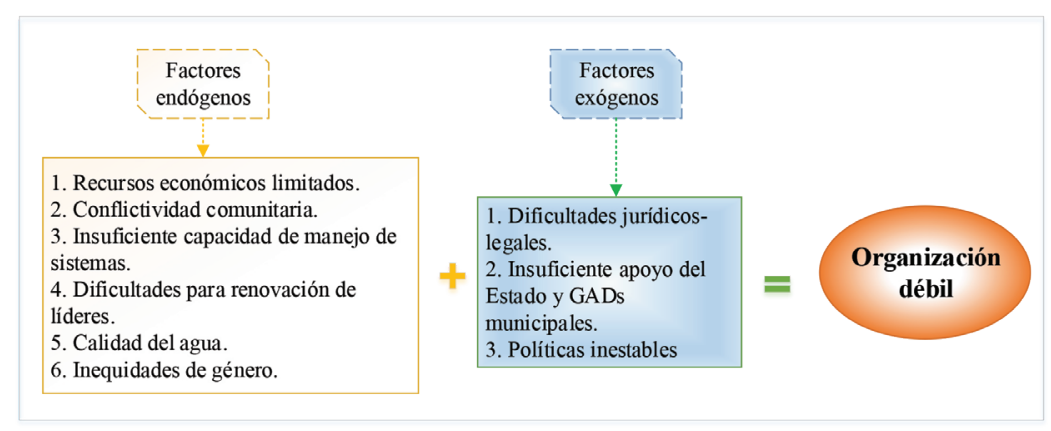

La capacidad de gestión y manejo del agua de las organizaciones con la participación de sus usuarios y los principios de solidaridad y equidad permite suplir la escasa presencia del Estado y enfrentar los factores endógenos que causan problemas al interior del territorio. Para suplir el déficit de recursos económicos la organización mantiene un sistema de aportes económicos de todos los usuarios cuando es 
necesario, por ejemplo: para complementar o reparar la infraestructura del sistema de manera que mejore la calidad del agua, se aporta económicamente y con los trabajos comunitarios "mingas".

La conflictividad comunitaria en algunos casos tiene sus orígenes en disputas por las fuentes de agua que se encuentran hidrográficamente en un mismo territorio. La Ley de Recursos Hídricos al exigir la creación de las Juntas Administradoras de Agua Potable para emitir la autorización de uso del agua abre disputas entre comunidades, prevaleciendo los ejercicios de poder basado en el dinero, es decir, cuando existe un litigio de este tipo, las comunidades que tienen mayor opción de ganar son las que pueden costearse abogados, y en ocasiones sobornar a técnicos y jueces. En otros casos se ponen en ejercicio practicas consuetudinarias en base a la capacidad de diálogo, que permiten a las organizaciones superar este tipo de conflictos, incluso les permite unir sus potencialidades para plantear proyectos conjuntos a problemas comunes como la escasez del agua.

Las comunidades andinas logran establecer sistemas organizacionales que reconoce y maneja procedimientos que les permite superar las diferencias según las realidades locales; es decir, pasar de los intereses personales y grupales a los intereses comunitarios, de los disensos a los consensos. Las asambleas y principalmente las mingas son los espacios idóneos de diálogo y de planificación para la gestión y manejo comunitario del agua.

Para incrementar las capacidades de gestión y manejo del agua, las organizaciones comunitarias tienen que considerar dos aspectos: el relevo generacional y la equidad de género, de manera que sea sostenible en el tiempo. La permanencia de los líderes en sus cargos a veces obedece a intereses personales que ven en las organizaciones comunitarias como medios para percibir recursos económicos o con fines de reconocimiento político. También hay poco interés de los jóvenes en involucrarse en los espacios de gestión y manejo del agua, aludiendo lo complejo que es desempeñar este tipo de delegaciones sin ningún reconocimiento económico, "estas funciones son honoríficas". La par- 
ticipación de la mujer en los cargos de las directivas de las organizaciones es baja, pues se ha construido socialmente la idea que la gestión y manejo del agua es una función de los hombres, debido a que las actividades son fuera del hogar y de la comunidad. Así, en la gestión comunitaria del agua los jóvenes son excluidos porque carecen de experiencia y las mujeres porque no es su espacio. Así, en el tiempo de vida del Consejo de Juntas ha sido baja la participación de la mujer.

Muchas JAAP que son parte del Consejo de Juntas han dado avances cualitativos importantes, superando los problemas endógenos, siendo en cierta medida autosuficientes en la gestión y manejo del agua, tanto de la infraestructura como del cuidado de fuentes y la administración de los recursos económicos. Esto es posible cuando hay capacidad económica de la organización o cuando la organización tiene capacidad técnica y administrativa con un alto grado de conciencia y participación de los usuarios, de jóvenes y mujeres insertadas en los diferentes niveles directivos de la organización.

Ciertas JAAP tienen limitaciones para afrontar con prioridad, técnica y legalmente las nuevas exigencias del Estado para la gestión y manejo del agua. Entonces, no todas las organizaciones comunitarias del PPI están con las mismas capacidades para la gestión y manejo del sistema. Por lo tanto, para que haya una participación de las organizaciones en el sistema del PPI deben mejorar sus capacidades a lo interno, implementando procesos de capacitación organizativa y técnica de sus dirigentes y usuarios.

Para la aplicación de la gestión comunitaria del agua requiere incluir como ejes transversales la interculturalidad y la integralidad; esto implica combinar una visión tecnicista a una propuesta que articule los ámbitos sociales, ambientales, económicos, culturales y técnicos. No limitarse a la concepción que el sistema de agua potable es solo la infraestructura, sino también abordar la administración, operación y mantenimiento, el control y vigilancia de la calidad del agua, el manejo de aguas residuales, el cuidado de fuentes, el fortalecimiento organizativo e incrementar los conocimientos de los/as usuarios/as del agua. Se debe también incluir el eje de género, ya que 
el agua está relacionada con los roles productivos, reproductivos y de la vida comunitaria misma, que asumen las mujeres en los sectores rurales (Foro de los Recursos Hídricos, 2015).

Las organizaciones consideradas medianas (entre 100 y 200 usuarios) y pequeñas (menos de 100 usuarios) son las que necesitan más ayuda de los GAD Municipales. Para dar sostenibilidad al PPI se firmó un documento en donde acuerdan la cooperación entre los GAD Municipales y JAAP para realizar la gestión y manejo del sistema de forma conjunta: acuerdo público-comunitario. Es importante que se generen debates en las JAAP sobre los ámbitos de atención y alcances de los acuerdos, puesto que "no existen diagnósticos de necesidades de capacitación ni planes institucionales con estrategias y presupuestos significativos para fortalecer capacidades en la gestión comunitaria del agua" (Foro de los Recursos Hídricos, 2015).

Mejorar las capacidades de la organización es necesario para implementar la gestión comunitaria del agua, así, obtener resultados que mejoren el acceso, control distribución y uso del agua y su articulación sea efectivas entre el sector público-municipalidad, ministerios sectoriales, y con el sector comunitario que conoce por experiencia el cómo trabajar en el ámbito rural (Foro de los Recursos Hídricos, 2015). Es importante crear consensos y fortalecer el rol de cada uno dentro del proceso de gestión y manejo del agua (Bastidas \& García, 2002), el Consejo de Juntas implementó un sistema de dialogo, al interno y externo de la organización.

Para mejorar las capacidades de las organizaciones e incrementar la eficiencia de gestión y manejo del agua, son importantes las alianzas público-comunitarias que en cada cantón pueden establecerse, siempre y cuando se respeten las diferentes dinámicas implementadas en las organizaciones comunitarias. La alianza estará encaminada a revertir las limitaciones y debilidades de las organizaciones, así, se tendrán un efecto por sí mismo positivo en las capacidades de las JAAP al momento de su participación en la Empresa Pública Pesillo-Imbabura que va a administrar el sistema regional de agua potable (Figura 36). 
Figura 36

Alianza pública comunitaria en la mejora de capacidades de gestión y manejo comunitario del agua

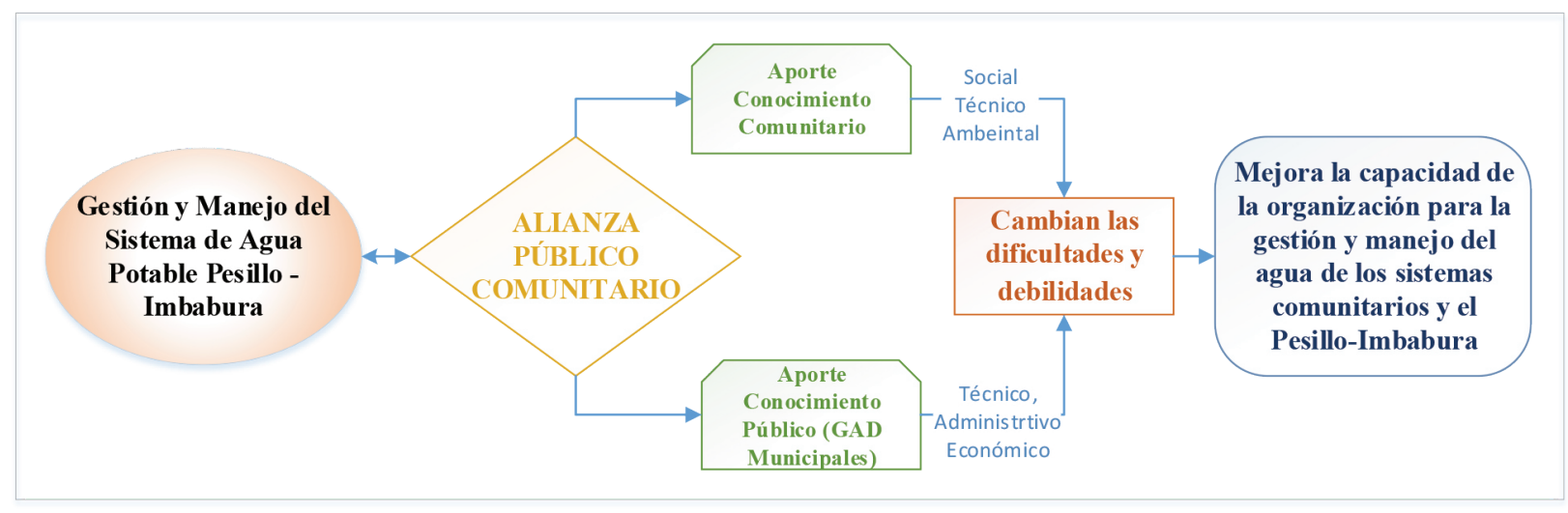


El articular y/o coordinar entre diferentes sectores se crea las condiciones para compartir conocimientos que se espera permita operar el sistema de agua potable de forma conjunta entre las organizaciones comunitarias y las instituciones públicas. La comunidad como la institución pública ha aportado a la consecución de los objetivos, la primera con sus conocimientos, su experiencia de la cotidianidad y la segunda con sus conocimientos y experiencia técnica y científico (Bastidas \& García, 2002).

La sostenibilidad de los servicios de agua potable dependerá de la organización y sus capacidades, técnicas, financieras y el diálogo entre los diversos (cohesión social), por lo que desde las instituciones públicas y de la sociedad civil deben generar acciones encaminadas a fortalecer esas capacidades, mediante procesos participativos e incluyentes en la toma de decisiones. Una de las acciones fundamentales es implementar procesos de capacitación en cada una de las organizaciones y de esa manera se rescaten los principios del Buen Vivir y de la sustentabilidad para maximizar la eficiencia de la gestión y manejo comunitaria del agua.

Si bien las JAAP gozan de muchas virtudes que hacen que la gestión y manejo del agua sea calificada como un modelo alternativo frente a las más comunes que hay en el Ecuador, también es cierto que se presentan dificultades que pueden atentar el continuar con esta práctica, debido a que la institucionalidad del Estado desconoce los principios y valores comunitarios. Por ello es necesario que las JAAP realicen un trabajo a su interior y detecten las debilidades y potencialicen sus capacidades, de manera que, al implementar las alianzas público-comunitarias con miras a mejorar las infraestructuras de los sistemas de agua, no elimine su identidad y cultura de gestión y manejo del agua.

Un proyecto que abarca varias comunidades con miles de usuarios y millonarias inversiones como el PPI tiene que contar con hombres y mujeres - en todas las organizaciones- capaces de gestionar y manejar el sistema, pues el proyecto trae consigo grandes retos que a 
140

futuro se pondrán a prueba, si las JAAP no están preparadas podrían enfrentar serias dificultades en los ámbitos sociales, ambientales, técnicos y económicos, generándose posibles conflictos entre los actores involucrados, por tal razón los GAD Municipales y JAAP deben trazar metas a corto, mediano y largo plazo enfocados en el mejoramientos de las capacidades locales para la gestión y manejo del sistema con un enfoque comunitario, que sea intercultural e integral.

La toma de decisiones en la gestión y manejo del sistema debe ser horizontal y no vertical. Si el usuario del agua participa en este proceso, sentirá que el sistema de agua potable del PPI es suyo y hará todo lo que le corresponda para que este sea sostenible en el tiempo y contar con agua segura tanto en calidad como en cantidad. La alianza pública-comunitaria debe innovar la forma de gestionar $y$ manejar el sistema y no ver al usuario como un cliente que hay que dotar de agua a cambio de una tarifa económica.

\section{Territorio y tejido social en la gestión y manejo del agua}

Un territorio se construye a lo largo de la historia sobre la base de asentamientos de una población en un espacio natural, se generan formas de producción y relaciones sociales con el medio natural. Una organización que gestiona y maneja el agua, afronta un complejo sistema de relaciones sociales, económicas, políticas, culturales y ambientales. En tal sentido los territorios étnicos son anteriores a la constitución del mismo Estado (Sánchez-Parga, 2007). Por lo tanto, las regulaciones de acceso, control, distribución, uso y disposición final del agua tienen que tomar en cuenta esos procesos históricos e incorporar en los lineamientos de gestión y manejo del agua al territorio como tal.

En la sociedad andina se distingue una matriz asociativa territorial (la llakta) cuyo espacio es compartido por asentamientos de familias pertenecientes a diferentes grupos de parentesco (el ayllu ${ }^{32}$ ), así, la

32 Familia nuclear y ampliada que vive en una comunidad indígena. 
dualidad territorio-familias (llakta-ayllu ${ }^{33}$ ) se reconoce como comunidad (Sánchez-Parga, 2007). El cuidado del territorio mediante manejos de páramos y fuentes de agua constituye parte de la memoria social del pasado y responsabilidad del presente. Por eso es que cuando se habla de comunidades, agua y territorio resultan ser inseparables (Isch \& Zambrano, 2015). Las comunidades del Consejo de Juntas del PPI mantienen una matriz natural agua y territorio y son las responsables de forjar relaciones sociales comunitarias, construyendo alrededor de estos elementos tejidos sociales entre - dirigentes, operadores, usuarios, representantes y técnicos de instituciones de la sociedad civil y públicas sean estas parroquiales, municipales, provinciales, nacionales e internacionales-.

Los pueblos originarios, que no sufren tanta fragmentación histórica en su cosmovisión, fueron construyendo sus propias formas de entender y actuar en su relación con la naturaleza y como son parte de esta. También el elemento vital el agua va generando relaciones espirituales en el que, el agua es tan aborigen ( $a b$-origine) como los pueblos, así, las fronteras entre la naturaleza, los seres humanos y los seres sobrenaturales se entrelazan en reciprocidades y respetos mutuos que aseguran la vida (Vargas, 2006) (Figura 37). No obstante, la mayoría de las instituciones cuando intervienen en las organizaciones lo realiza de forma separada, mas no consideran que para las comunidades indígenas un sistema se agua potable y/o de riego es complementario entre la comunidad, la naturaleza e infraestructura (Cachipuendo, 2017).

Las organizaciones de gestión y manejo del agua deben incorporar la noción territorial en la gestión e intervención de un proyecto de agua, considerando como componentes de un territorio: la naturaleza con el elemento agua y suelo, la infraestructura del sistema, al ser humano como ente social y espiritual. Numerosas experiencias demuestran que la gobernanza pública del agua fragmentada tie-

33 Familias asentadas en un territorio comunitario. 
ne efectos negativos, por lo que es necesario realizar esfuerzos para coordinar la gestión del agua de forma integral e intercultural en un territorio (Comité de Gestión Agua Chambo, 2015). Además, debe comprenderse que para las comunidades el manejo de su territorio está relacionada con su ejercicio de niveles de autonomía (Isch \& Zambrano, 2015), es decir, son capaces de gestar su Buen Vivir.

\section{Figura 37}

Relaciones sociales, económicas, políticas, culturales y ambientales en el territorio para la gestión y manejo del agua

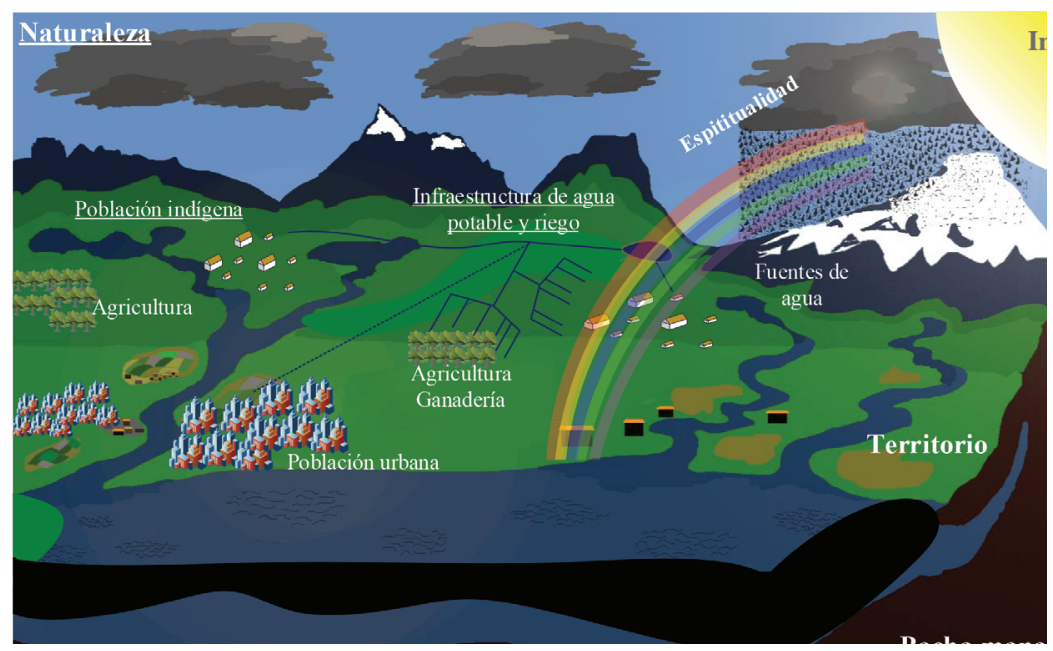

La gestión comunitaria del agua asumida por las organizaciones sociales refleja niveles de autonomía. En las comunidades, territorio y niveles de autonomía son construidos desde ejercicios de los derechos consuetudinarios que vienen forjándose desde tiempo atrás, y en tiempos más recientes el cuidado y manejo del agua, pues consideran al agua como un elemento perecedero que, si no se lo cuida, se acaba (Bastidas \& García, 2002), poniendo en riesgo la vida de los pobladores y resto de seres vivos. Razón por la cual el Consejo de Juntas propone que el PPI integre como eje principal el ambiental de forma que se generen políticas y proyectos de protección y conservación de las fuentes de agua. 
Pese a la autonomía de las comunidades para la gestión y manejo del agua, en un territorio que rebasa las fronteras geográficas de la comunidad, se generan dinámicas a partir de acciones entre varias organizaciones, de manera que sus miembros establecen una interrelación permanente con su entorno, factores que fortalecen el tejido social (Bastidas \& García, 2002), que para el caso del Consejo de Juntas se gesta un tejido social entre diferentes pueblos que se encuentran ubicados en diferentes territorios.

En el territorio, el agua se convierte en elemento indispensable en la construcción del tejido social entre los actores comunitarios, públicos, privados y de la sociedad civil. En el territorio ocurren conflictos por el acceso, control y uso del agua (consumo humano, riego, entre otros), porque no es abundante ni está presente en todos los territorios comunitarios. En comunidades que tienen fuerte influencia occidental (individualismo), han existido actitudes mezquinas, pero los principios ancestrales de sobrevivencia como la solidaridad prevalece, porque en la cosmovisión indígena los elementos de la naturaleza (pachamama ${ }^{34}$ ) deben ser compartidos tanto en su uso como en su cuidado.

En el caso de la JAAP regionales, la fuente de agua de una comunidad abastece a cientos de familias de otras comunidades. Este tipo de organizaciones comunitarias han visto fortalecer los tejidos sociales intercomunitarios y el cuidado del agua crea nuevas nociones de territorialidad, como un espacio que todos deben involucrarse para su gestión y manejo, aunque jurídicamente pertenezca a una comunidad "el agua no tienen fronteras construidas por el ser humano". El territorio para las comunidades es la casa grande en donde los seres humanos y no humanos acuden para cubrir necesidades elementales como el abastecerse de agua.

El tejido social en un proyecto multipropósito necesariamente inicia desde las fuentes de agua, así, para el caso del PPI es indispensa-

34 Madre naturaleza. 
144

ble que se introduzca el enfoque de territorio indígena, en el cual se involucran los territorios de los pueblos: Kayambis, Otavalos, Natabuelas y Karanquis. Entonces, todas las organizaciones involucradas en el proyecto deben aportar en el manejo y cuidado del territorio hídrico ubicados en la estribación del nevado Cayambe, la unidad de cuenca de la laguna de San Marcos y del río La Chimba, cuyo propósito es la eficiencia técnica, social, ambiental y económica del uso del agua.

Es importante tomar en cuenta el enfoque de territorio en el modelo de gestión y manejo del sistema con la participación de los/as usuarios, representados por: los Municipios agrupados en la Mancomunidad y a nivel de las comunidades por el Consejo de Juntas. Esta inclusión de las comunidades dará sostenibilidad social al proyecto ya que todas las JAAP comunitarias, siempre estuvieron involucradas, desde que el proyecto inició, miles de personas participaron en su ejecución, aportando con mingas en los trabajos para los estudios de captación del agua en ríos concesionados, siempre manteniendo la preocupación por la sostenibilidad de las fuentes hídricas, de esta manera al ser un proyecto regional trasvasa la cuenca hidrográfica convirtiéndose en cuenca social, es decir que por intervención del ser humano mediante la infraestructura se conduce el agua de una cuenca hidrográfica hacia otras (Cachipuendo, 2013). El agua del PPI se capta de ríos que hidrográficamente de forma natural van hacia la Amazonia.

La construcción del tejido social en proyectos que abarcan poblaciones que van más allá de los territorios comunitarios y de las JAAP, con una característica en que las fuentes de agua se encuentran fuera del territorio de la cuenca hidrográfica, son elementos que se puede pensar en territorios hidro-sociales, sitios en los cuales existe una interacción entre el ser humano y la naturaleza, siendo los usuarios del agua del PPI los que deben seguir mejorando las acciones de resguardo de las zonas de generación del agua. Entonces, la Empresa Pública Pesillo-Imbabura como la Organización Consejo de Juntas deben coordinar las políticas, estrategias y proyectos de intervención, manteniendo los principios comunitarios. 
Para que haya claridad de los roles y funciones que cumplen los diversos involucrados en un proyecto de características regionales (territorio hidro-social) es necesario implementar un plan de gestión territorial del agua, para que, las acciones de todos los actores que tienen alguna competencia, responsabilidad o interés en relación con el agua en el territorio, actúen sin duplicar actividades, peor aún sobreponer roles que conllevan a la generación de conflictos. Las organizaciones sociales, los municipios, los habitantes (usuarios/as) de las cabeceras parroquiales y cantonales se articulen potencializando el tejido social en todo el espacio territorial del proyecto, desde Cayambe-Pedro Moncayo por el sur, hasta Ibarra en el norte de la provincia de Pichincha.

\section{Gobernanza y gobernabilidad en la gestión comunitaria del agua}

La gobernanza y gobernabilidad son conceptos que se generan para relacionar las acciones implementadas en la gestión y manejo del agua por parte del Estado y sus instituciones con la sociedad civil. Sin embargo, según Murillo-Licea y Soares-Moraes (2013) consideran que la gobernanza es "cuando nos refiramos a la acción conjunta del gobierno y la sociedad para un objetivo positivo común (como el desarrollo), a fin de alcanzar un equilibrio", mientras que se refiere a la gobernabilidad "cuando se trate de la parte institucional conferida al gobierno y sus instituciones, es decir, su capacidad y rango de acción”.

Estos conceptos son generados desde la visión occidental que son impuestos a los territorios locales, que, para el caso del agua, provoca conflictos entre instituciones del Estado y las organizaciones comunitarias. Las organizaciones comunitarias por experiencias acumuladas generan formas propias de gestión y manejo del agua y se respalda en los procesos de cogobierno, autodeterminación, autogobierno y gobierno comunitario, formas que se encuentran respaldadas por la Constitución del Ecuador (Figura 38). 
146

Figura 38

Perspectivas para la construcción de esquemas de gobernanza y gobernabilidad comunitaria del agua

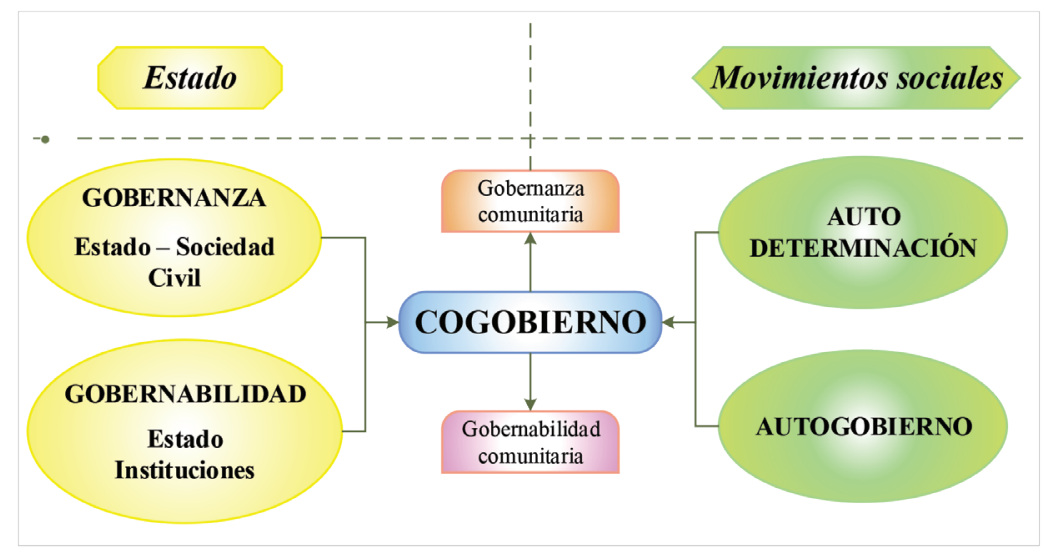

Gobernanza comunitaria del agua

El Consejo de Juntas con su dinámica social logra establecer relaciones con las instituciones del Estado mediante constantes diálogos y consigue la consecución del PPI, en ese contexto la gobernanza del agua se construye a través de procesos de diálogo e interacción entre organizaciones formales e informales; agentes estatales y no estatales, los cuales definen, a diferentes escalas, nuevas estructuras socio-hidrológicas, que configuran el acceso, control y uso del agua y sus territorios (Duarte, Hoogesteger \& Yacoub, 2016).

Entonces, en las organizaciones comunitarias la gobernanza se presenta como las interacciones entre estructuras, procesos y tradiciones que determinan como se ejerce el poder y las responsabilidades, como se toman las decisiones y como intervienen los comuneros (usuaria/os del agua) y otros actores en la gestión y manejo de sistemas de agua de consumo humano. Incluye los mecanismos, procesos e instituciones mediante los cuales los usuarios expresan sus intereses, ejercen sus derechos, satisfacen sus obligaciones y resuelven sus dife- 
rencias (Cobo, Yaguache, Piñeiros, Calisto \& Gay de Montella, 2018). También se puede entender como sistemas políticos, sociales, económicos, ambientales y administrativos que afectan, directa o indirectamente la gestión del agua y la prestación de servicios de agua a diferentes niveles de la sociedad (Comité de Gestión Agua Chambo, 2015).

La prestación del servicio del agua por organizaciones comunitarias atraviesa las estructuras, procesos, tradiciones e instituciones, como también los sistemas políticos, sociales, económicos, ambientales, tecnológicos y administrativos con participación directa de los usuarios del agua en todos los procesos y niveles de decisión; en estos contextos, las organizaciones comunitarias encuentran formas propias de gestionar y manejar los sistemas de agua potable respaldándose en el enfoque de la gestión comunitaria (Figura 39).

Figura 39

Elementos de la gobernanza comunitaria del agua

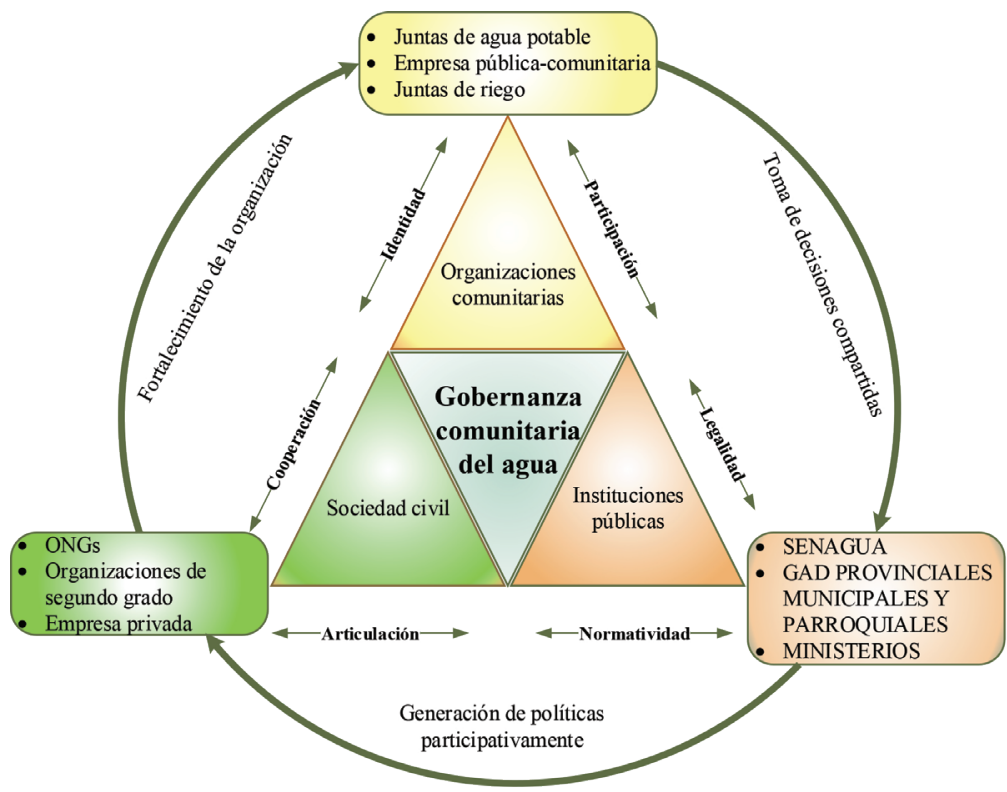


Las organizaciones comunitarias de base del Consejo de Juntas quienes impulsa el PPI seguirán ejerciendo la gobernanza del agua en sus territorios para garantizar su acceso. Sin embargo, es necesario reflexionar sobre la gobernanza del agua con la Empresa Pública de Agua Potable Pesillo-Imbabura (el ramal principal) en territorios que históricamente han ejercido la gobernanza comunitaria a excepción de las cabeceras parroquiales y cantonales que ejercen un modelo de gobernanza pública del agua.

En el mejor de los casos, si las alianzas públicas-comunitarias son alternativas para superar las debilidades y limitaciones de las organizaciones comunitarias; los principios de la gobernanza pública ejercidas a través de las Empresas Municipales de Agua Potable en cada cantón y la gobernanza comunitaria con sus principios y valores deberían unirse, ya que algunos aspectos son comunes, y ambos representan potencialidades que pueden aportar a la gestión y manejo eficiente del agua.

Aunque la mayoría de los usuarios y dirigentes de la JAAP están inconformes porque, para la administración, operación y mantenimiento del Sistema Regional de Agua Potable Pesillo-Imbabura, la mancomunidad de municipios creará la denominada Empresa Pública de Agua Potable Pesillo-Imbabura (EPAP Pesillo-Imbabura) con participación comunitaria, situación que desde las organizaciones comunitarias cuando gestaron el proyecto no lo tenían pensado. Las condiciones impuestas para el financiamiento del proyecto obligaron aceptar esta forma de gestión del agua. La empresa tendrá cinco representantes en el directorio, tres de los municipios y dos de la Organización Proyecto Pesillo-Imbabura (de las JAAP regionales). Esto supone que la conducción principal del sistema de agua, dentro del proceso de gobernanza, la gestión y manejo será pública, cuando el sueño y reto de las organizaciones fue implementar un sistema de gobernanza que fortalezca la gestión y manejo comunitaria del agua.

En un país que tiene el carácter de ser plurinacional e intercultural, la gobernanza del agua se implementa en un sistema de diálo- 
go con todos los actores, porque a criterio de José Juncosa, vicerrector de la UPS, implica el respeto con equidad en la convivencia entre pueblos y nacionalidades. Al mismo tiempo, la gobernanza propone que sus culturas políticas y económicas sean respetadas y tomadas en cuenta como una posibilidad de ser implementada en el resto de la nación, sobre todo por aquellos que no se reconocen como indígenas (Boletín Salesiano, 2019, p. 3).

La gobernanza comunitaria del agua implica que su gestión y manejo realizada por las comunidades indígenas desde hace mucho tiempo con sus propias dinámicas socioculturales, ambientales, políticas, tecnológica y económicas, no sea mirada como un proceso ineficiente desde el punto de vista tecnológico. En ese sentido desde las comunidades se impulsa que la Empresa Pública de Agua Potable Pesillo-Imbabura (EPAP Pesillo-Imbabura) adopte en sus políticas y planificación los principios y valores de la gestión comunitaria del agua y establecer un proceso de gobernanza del agua intercultural e integral.

Establecer un sistema de gobernanza del agua con una visión comunitaria es uno de los pilares para garantizar la sostenibilidad y conservación del agua en el territorio de los proyectos multipropósitos. Por eso, es importante la articulación plena al elaborar políticas, planes y programas entre las diferentes instituciones que fomenten la participación, que asegure la representación y en la negociación se involucren todos los actores y den a conocer sus intereses (Cobo et al., 2018), mismos que finalmente se conviertan en objetivos comunes.

El ejercicio de la gobernanza con visión comunitaria se produce cuando las normas y prácticas sociales empoderan y estimulan a las personas a tomar cada vez más control sobre su propio destino de una manera que no afecta negativamente a los derechos de los demás (Cobo et al., 2018). Las organizaciones comunitarias con la concreción del PPI pretenden contribuir al Sumak Kawsay de las comunidades indígenas y la población urbana del norte ecuatoriano. 
150

\section{Gobernabilidad del agua en comunidades rurales}

La gobernabilidad se refiere a la capacidad de las instituciones representantes del Estado en el diseño de políticas públicas que sean socialmente aceptadas, orientadas a la sostenibilidad del recurso hídrico, así como hacer efectiva su implementación junto a los diferentes actores involucrados. En síntesis, implica la capacidad de generar las políticas adecuadas, y de llevarlas a la práctica de manera que la gestión del agua sea eficiente (Peña \& Solanes, 2002).

La gobernanza del agua en las comunidades indígenas tiene éxito porque hay un escenario de gobernabilidad por voluntades de las instituciones públicas y presión de las organizaciones comunitarias, para que se practiquen procesos de: coordinación, colaboración y entendimiento entre los actores de las organizaciones que ponen en práctica el derecho propio o consuetudinario apoyadas en la costumbre, la tradición, y en las instituciones del Estado que regulan sus actuaciones.

Para ejercer gobernabilidad del agua en los diferentes territorios, los actores conocen cuáles son sus roles. El Estado tiene el rol de regulador según la Ley de Recursos Hídricos a través de la SENAGUA en un territorio la Demarcación Hidrográfica; las JAAP tienen el rol de gestionar y manejar el sistema para dotar de agua a las poblaciones que dependen de ella o que pertenecen a la organización comunitaria.

Las JAAP como organizaciones comunitarias implementan procesos de gobernabilidad que permiten desarrollar acciones de gestión comunitaria del agua en un marco de coordinación, colaboración y entendimiento entre los diferentes, es decir la práctica de la interculturalidad, de manera que se impulsa el manejo sostenible del agua en los territorios a favor de las comunidades y colectivos sociales.

La participación y el protagonismo en la toma de decisiones de los usuarios en la organización son claves, para evitar crisis de gobernabilidad o situaciones que puedan debilitar las condiciones para 
la buena gobernanza del agua. Estas características propias de la gestión comunitaria se espera que sean implementadas en la Empresa Pública de Agua Potable Pesillo-Imbabura (EPAP Pesillo-Imbabura).

Una condición básica para la gobernabilidad es que los diversos actores relacionados con la gestión del agua tengan voz directa o de forma representativa en la toma de decisiones, a través de instituciones legítimas y legales que representen a los intereses e intenciones de los usuarios/as del agua de las comunidades y colectivos sociales. Es indispensable asegurar la participación efectiva de diversos actores: mujeres y hombres; jóvenes y adultos; representatividad geográfica, entre otros, este involucramiento asegurará la gobernabilidad del agua en los territorios comunitarios (Cobo et al., 2018).

En las JAAP donde la participación u otras acciones tengan limitaciones, es indispensable mejorar los procesos de toma de decisiones para el fortalecimiento de la gobernanza. La descentralización y participación efectiva de los diversos actores son claves en la gestión del agua, así como cambiar las formas tradicionales de gobernanza del agua, de modelos "de arriba hacia abajo" a modelos "de abajo hacia arriba" (Cobo et al., 2018). Los modelos de gestión horizontales impulsan la igualdad y equidad entre los actores y en territorios comunitarios deben respetar las dinámicas de la vida comunitaria donde lo común esta sobre lo individual.

Las condiciones impuestas por los organismos del Estado y la cooperación internacional impulsan un proceso de gobernabilidad con una visión de arriba hacia abajo en la cual los usuarios no tienen poder de decisión. Así, para financiar la ejecución del proyecto, los representantes de las JAAP regionales, los dirigentes del Consejo de Juntas del PPI, alcaldes de los GAD Municipales, Banco del Estado, entre otros, proponen que, para la administración, operación y mantenimiento del Sistema Regional de Agua Potable Pesillo-Imbabura, se cree la denominada Empresa Pública de Agua Potable Pesillo-Imbabura (EPAP Pesillo-Imbabura) con participación comunitaria, esta propuesta no es generada desde la visión comunitaria. 
152

La gestión y manejo del agua se convierte un centro de poder y es ejercido generalmente por las organizaciones o instituciones que manejan los recursos económicos, generándose inconformidades por parte de las organizaciones comunitarias que no cuentan con los recursos económicos necesarios para manejar eficientemente el sistema. En el PPI las propuestas de las organizaciones comunitarias que clamaban la gestión comunitaria no fueron tomadas en cuenta, se convirtió en una participación sorda y las decisiones habían sido planificadas con anterioridad por parte de la mancomunidad de municipalidades y las instituciones que financiaron el proyecto; en palabras sencillas, las decisiones son verticales y jerárquicas siendo la participación de las comunidades solo parte de un trámite para avalar lo actuado por los otros actores. Esta forma de gobernanza del agua desvaloriza la participación efectiva de los usuarios/as, atentando con los principios democráticos, característica de la gestión comunitaria del agua. Este tipo de procedimientos conlleva a la generación de políticas desarticuladas al sistema de vida comunitaria (Peña \& Solanes, 2002), lo que puede provocar dificultades en los procesos de gobernabilidad del agua, que en muchas ocasiones las organizaciones se ven obligadas a desconocer a los organismos de control y de rectoría del agua del país.

La imposición de políticas, acciones, etc., generan problemas de gobernabilidad y conflictividad, porque las voces de la mayoría no son tomadas en cuenta. Sin embargo, como son procesos sociales siempre se dan en marco de tensiones y disensos, que pueden también entenderse como oportunidades, de forma que las condiciones de gobernabilidad parten desde situaciones negativas que en base al diálogo se convierten en positivas para dar sostenibilidad al acceso, control y uso del agua.

Entonces, las condiciones de gobernabilidad de los sistemas de agua potable Pesillo-Imbabura dependen de las formas de la toma de decisiones que sean un modelo de abajo hacia arriba y/o horizontales, de tal manera que las políticas y acciones que se implementen se 
construyan conjuntamente entre todos los actores del Estado, organizaciones comunitarias y de la sociedad civil.

La articulación de las acciones colectivas, públicas y comunitarias posibilitará una planificación efectiva en donde los principios y valores de la cosmovisión andina de los pueblos indígenas y acogiendo lo que determina la ley conllevan a plasmar una gestión y manejo del agua con solidaridad, equidad y armonía con la naturaleza.

\section{La gestión comunitaria del agua un proceso en construcción}

La gestión comunitaria del agua enunciada en la Constitución y Ley de Recursos Hídricos pretende reconocer las dinámicas de su gestión y manejo implementadas desde hace años por las comunidades indígenas andinas. Con la experiencia de las comunidades para acceder, controlar, distribuir, usar y la disposición final del agua con sus propias dinámicas, conlleva a un análisis propio de la cosmovisión indígena andina que repercute en algunos elementos conceptuales, valores y principios de los paradigmas de la sustentabilidad y el Buen Vivir. Así, se puede considerar que la gestión comunitaria del agua es, un enfoque propio de las comunidades que mantienen una identidad y se acogen elementos conceptuales de otros enfoques como la eco-hidrología, la hidro-sociología, el metabolismo socio ambiental, la gestión integral, etc., que en varios aspectos posiblemente confronta a enfoques conceptuales introducidos de países hegemónicos.

Una de las principales características del enfoque de la gestión comunitaria del agua, es la relación que existe entre los usuarios del agua que viven en comunidad, no solo compartiendo un espacio geográfico o una infraestructura de un sistema de agua potable o de riego, sino que existe una relación de vida, entre seres humanos y resto de seres, donde lo espiritual es parte de esta relación. Entonces, un sistema de agua para consumo humano está compuesto por tres elementos fundamentales que se relacionan y se complementan, la comunidad, la naturaleza y la infraestructura física (Figura 40), 
154

elementos que también se aplican para el caso de sistemas de riego comunitarios (Cachipuendo, 2017).

\section{Figura 40}

Características y principios de la gestión y manejo de sistemas de agua comunitarios

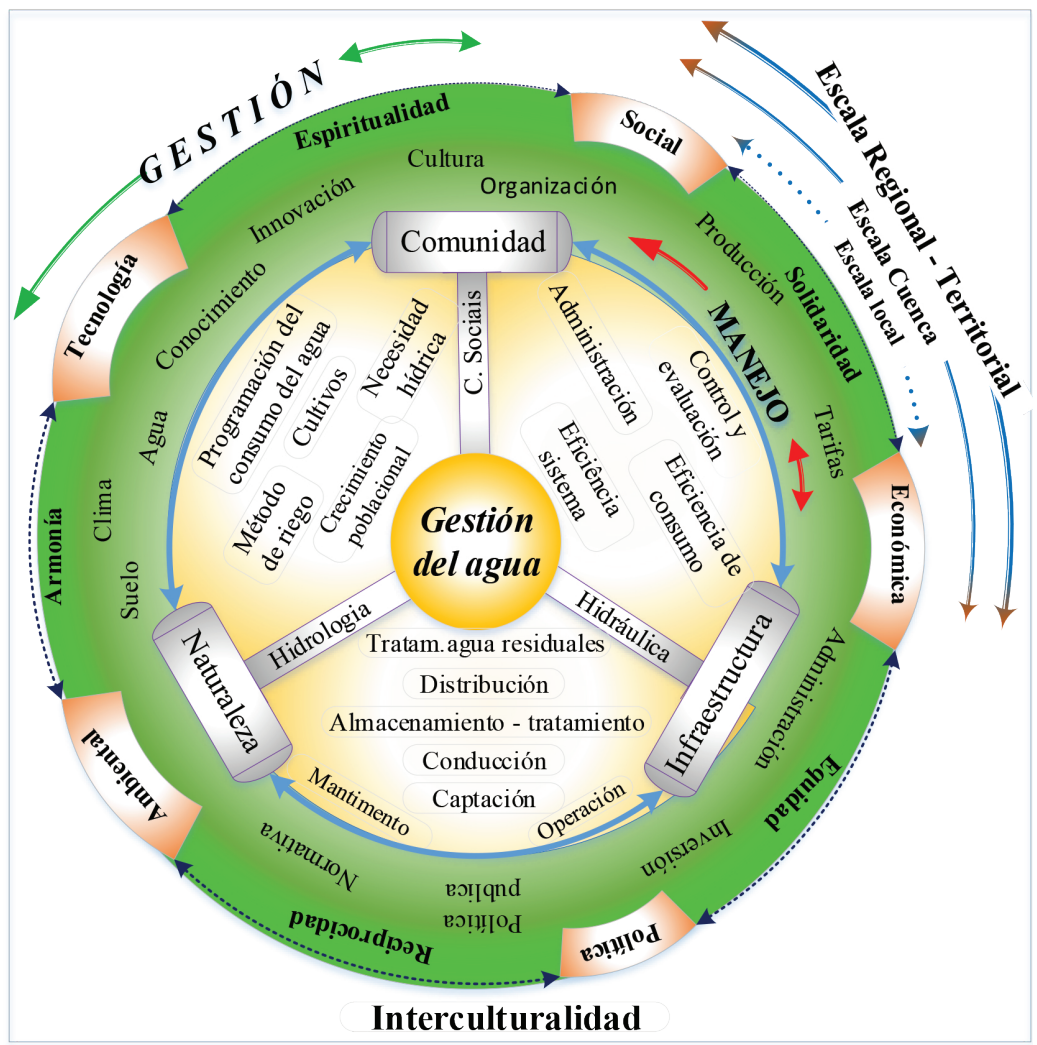

Fuente: Cachipuendo (2017)

En la comunidad, las decisiones y acciones implementadas para los procesos de acceso, control, distribución, usos y disposición final del agua, son tomadas y compartidas con todos los usuarios, estos no solo reciben un servicio de dotación de agua, por lo contrario están 
pendientes de su sistema, manteniendo una visión integral e intercultural sintiéndose parte de este, por ejemplo, para la conservación de las fuentes de agua, todos los usuarios salen a las mingas para realizar actividades de protección, cosa igual ocurre para el mantenimiento de la infraestructura del sistema.

La naturaleza, en dependencia de los ciclos climáticos y cobertura vegetal es proveedora de agua en un territorio comunitario, siendo los ecosistemas altoandinos (páramos) en donde mayormente se genera el agua. En estos territorios existen comunidades que por razones de la reforma agraria tienen títulos de propiedad individual, que con fines económicos se implementan actividades agropecuarias que amenazan las fuentes de agua. Ante los cambios naturales y sociales desde años atrás, las comunidades van siendo conscientes de estas realidades e implementan sistemas de conservación y protección de sus fuentes de agua, implementando sus propias regulaciones de uso de suelo con el principio fundamental que el beneficio comunitario está sobre el individual.

El agua para ser usada, la comunidad con apoyo de instituciones públicas y de la sociedad civil construyen infraestructura para captar, conducir, almacenar, tratarla, distribuirla en cada una de las viviendas, y en los últimos años también se encargan de la disposición final de las aguas residuales. Los saberes de las comunidades y la tecnología actual deben converger con el propósito que la infraestructura se encuentre en condiciones que asegure el agua en cantidad y calidad para el ser humano y devolverla a la naturaleza en condiciones que mantenga la vida de otros seres. Sin embargo, el sistema organizativo comunitario y público en ciertas ocasiones en dependencia del tamaño del sistema tienen dificultades en realizar procesos de control y vigilancia de la calidad del agua. Esta realidad se debe a diversos factores, entre otros a la debilidad institucional del Estado quien tiene las competencias en apoyar estos procesos en las comunidades.

Las organizaciones comunitarias andinas acceden, controlan, distribuyen, usan y realizan la disposición final del agua con el fin de 
satisfacer las necesidades de la población. Para mantener este elemento en el tiempo y dotar de agua a las futuras generaciones, implementan acciones sistémicas, integrales, con una visión de interculturalidad lo que fortalece el enfoque de la gestión comunitaria del agua. En este contexto, en un sistema de agua potable que tienen cobertura territorial intra e intercomunitaria se observan prácticas y acciones que permiten diferenciar lo que es gestión y manejo del agua.

\section{Gestión de sistemas comunitarios de agua de consumo humano}

En los sistemas comunitarios de agua de consumo humano, la gestión puede ser considerada como el correcto acceso, control, distribución y uso eficiente del agua (Cachipuendo, 2017), para el caso de las organizaciones de agua potable también se incluye su disposición final. La finalidad de la gestión es implementar acciones que permiten dotar de agua tanto en cantidad como de calidad a todos/as las personas que habitan en un territorio, de forma equitativa, solidaria, incluyente, con identidad, en armonía con la naturaleza y dialogando con los diferentes actores involucrados al externo como al interno del territorio de influencia del sistema y finalmente devolver el agua a la naturaleza en condiciones que siga generando vida.

Las organizaciones comunitarias del Consejo de Juntas que dotan de agua de consumo humano, por medio de sus representantes (dirigentes) realizan diferentes acciones que pueden ser consideradas como parte de la gestión del agua: 1) cumplir las normativas legales de acceso, control y vigilancia de la calidad del agua, 2) negociación de proyectos, 3) participación en la generación de la política pública, 4) participación en reuniones de planificación con los organismos de control y 5) velar por el buen manejo del sistema y de la disposición final del agua mediante un sistema del constante fortalecimiento organizativo (Figura 41). 
Figura 41

Acciones de la gestión de agua en territorios comunitarios

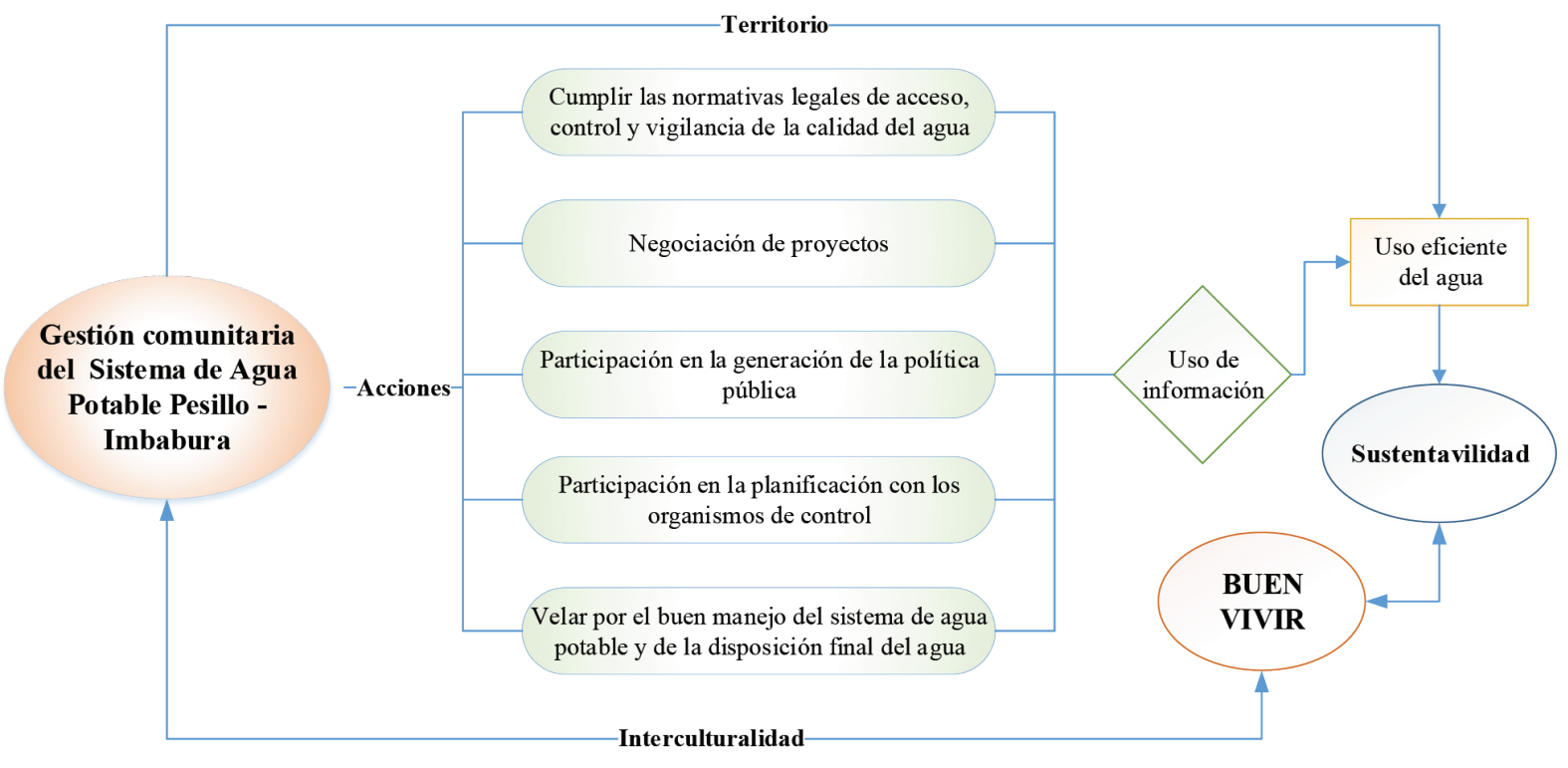


Para dar sostenibilidad a los procesos de gestión, la participación de todos/as los usuarios/as es fundamental, misma que se realiza mediante la toma de decisiones en las asambleas y se delega a los dirigentes para la puesta en marcha su cumplimiento, quienes son sujetos a procesos de veeduría y rendición de cuentas que también se conoce como la fiscalización del manejo de los recursos económicos de la organización.

\section{Manejo de sistemas comunitarios de agua de consumo humano}

De las prácticas de manejo de los sistemas comunitarios de agua de consumo humano implementadas por las JAAP del PPI se puede considerar "manejo" a las actividades encaminadas al uso eficiente de los diferentes componentes del sistema sea en la infraestructura, en la naturaleza y en las relaciones sociales entre usuarios. En los procesos de manejo del sistema se incentiva la participación de todos los usuarios/as, manteniendo una visión integral e intercultural; las actividades son impulsadas por los dirigentes y/o delegaciones emitidas por la asamblea de los usuarios/as del agua.

Las principales actividades que la organización comunitaria realiza para un correcto manejo del sistema están encaminadas a: 1) la conservación de fuentes de agua, 2) la operación y mantenimiento de la infraestructura del sistema considerando desde, la captación, conducción, almacenamiento, tratamiento, distribución domiciliaria del agua, 3) el control y vigilancia de la calidad del agua, 4) la administración económica del sistema y 5) la operación y mantenimiento del sistema de saneamiento (Figura 42).

\section{Características de la gestión y manejo comunitario del agua}

La gestión comunitaria del agua como una propuesta de valorización de antiguas prácticas que mantienen las comunidades indíge- 
nas para hacer uso de los elementos de la naturaleza. Es característico que las comunidades se organicen con base a la cooperación entre sus miembros, buscando la satisfacción de las necesidades humanas (Sandoval \& Gunter, 2013, p. 167). Es un claro ejemplo de como las comunidades del Consejo de Juntas que se unen para enfrentar la escasez de agua, y manteniendo sus dinámicas de vida comunitaria impulsaron una alternativa de solución a sus problemas con la ejecución del PPI.

\section{Figura 42}

\section{Actividades de manejo del agua en territorios comunitarios}

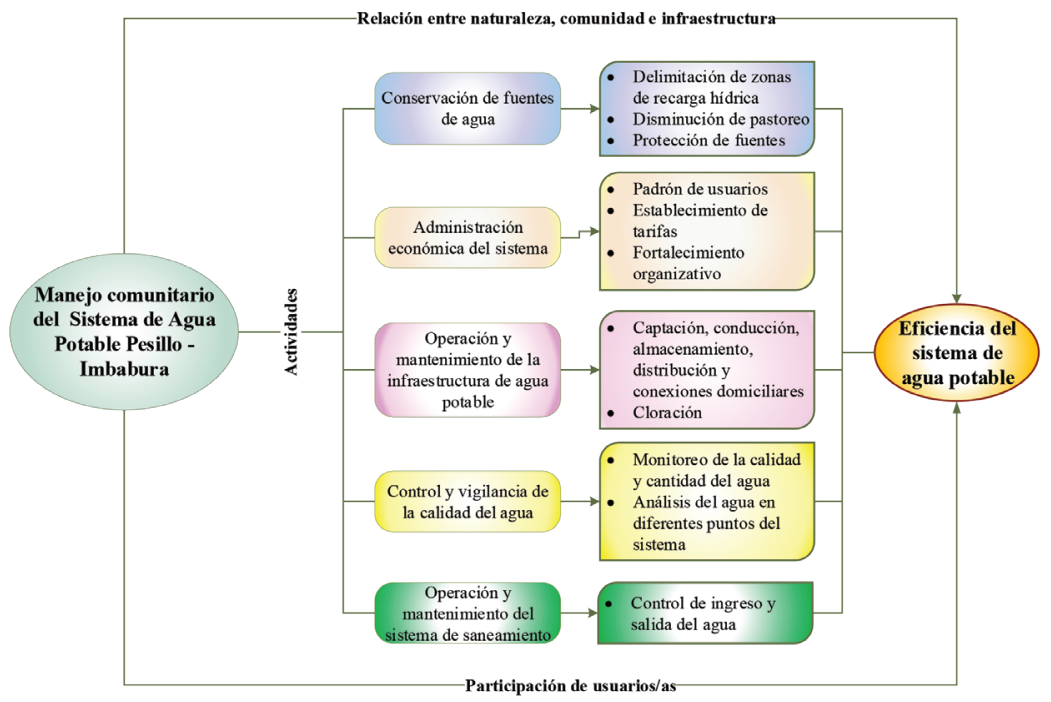

La gestión comunitaria también está relacionada con la autogestión, en el sentido de que es una propuesta holística basada en una racionalidad diferente a la dominante, que promueve otra concepción de la naturaleza y de las relaciones entre los seres humanos y la naturaleza no humana. Concibe el agua como un elemento constitutivo de la trama sociocultural y natural. 
Alude también a la organización que implementa acciones de gestión y manejo del agua desde lo local, en cuanto a su acceso, control, distribución, uso y disposición, sin perder el contexto nacional, regional o global, para lo cual se pueden establecer procesos de cogobierno. La gestión comunitaria del agua respalda a las organizaciones el ejercicio de autoridad ante los actores locales sobre el agua, respaldados en los derechos colectivos en el territorio, entendiendo por actores locales como el conjunto de individuos agrupados en comunidades, asociaciones, juntas de agua, comités, etc., pero que cumplan la principal característica: e interactúen que tengan un régimen de vida comunitaria e interactúan en un territorio común, en los cuales intercambien recursos-materiales, de información y de capacidades, según marcos socioculturales que les permite tener una lectura de su entorno y certidumbre para actuar en el territorio comunitario (Sandoval \& Gunter, 2013).

El enfoque de la gestión comunitaria del agua brinda a las organizaciones comunitarias elementos para implementar acciones de gestión y manejo del sistema de agua de consumo humano, que permita enfrentar la escasez del agua, las dificultades de recursos económicos para la operación, mantenimiento y control de la calidad, la dificultad de renovación de líderes, juicios legales, inequidades de género y generacional entre otros aspectos (Foro de los Recursos Hídricos, 2013).

El enfoque de la gestión comunitaria del agua también permite identificar una serie de prácticas que coexisten paralelas; la solidaridad para reconocer el problema, pero también para buscar soluciones; la desconfianza en sus líderes e instituciones, la cooperación entre grupos del mismo sexo, pero su poca cooperación con el sexo contrario, un liderazgo poco rotativo y excluyente, y una organización muy débil (Bastidas \& García, 2002), situaciones que en las condiciones actuales de reivindicación de los diferentes derechos se están superando por parte del Consejo de Juntas y respaldadas por la SENAGUA, se consideran puntos críticos que las organizaciones comunitarias tienen como prioridad superarlas y poder ser parte de la gestión y manejo del sistema del PPI. 


\section{La gestión comunitaria del agua en el PPI}

La gestión comunitaria pretende que la población en general cuide el agua y a través de las instituciones y organizaciones encargadas de gestionar y manejar los sistemas de agua potable garanticen la provisión de este líquido a futuro, para lo cual todos/as deben encaminar actividades a su cuidado y uso eficiente. En las comunidades rurales, el ejercicio del derecho humano al agua ha sido posible cristalizar a través de la gestión comunitaria, con un principio fundamental como la participación plena de los usuarios desde la concepción de la idea del proyecto, construcción, ejecución, gestión y administración de los sistemas de agua.

La gestión comunitaria permite a los individuos, en el caso del PPI a los futuros usuarios participar en las etapas del proyecto: idea, gestión, ejecución; sin embargo, las comunidades se encuentran dialogando para que también participen en la gestión y manejo (administración) de los sistemas comunitarios de agua construidos con la fuerza de trabajo de todos/as.

No obstante, los modelos de gestión comunitaria tienen resultados diferentes en la prestación del servicio de dotación de agua, debido a las diversas características de las organizaciones, que en base a su fortaleza organizativa y legitimidad ponen en práctica los principios comunitarios. La gestión y manejo comunitario del sistema de agua potable implementada por las organizaciones no es igual en los diferentes territorios, tampoco está exenta de intereses, conflictos y dificultades, porque son procesos sociales en construcción y de reconocimiento de derechos.

Un sistema de agua potable es una construcción socio-natural que políticamente no es neutral, más bien se generan relaciones de poder social (Perreault, 2015), por lo que, no está demás decir, que en la gestión comunitaria del agua se crean relaciones de poder horizontales reivindicativos de los sectores olvidados por el poder económico predominante y el Estado. Cuando en territorios comunitarios 
existe escasez de agua, basados en el derecho humano se construyen sistemas socio-naturales acoplados que doten agua a todos y todas.

La organización comunitaria en el proceso de construcción del proyecto de agua potable Pesillo-Imbabura en todas sus etapas invita a los diversos actores a que participen. Así, los usuarios estuvieron en la concepción de la idea y ejecución de la inversión, aportando con dinero y participando en mingas. La persistencia de los líderes permitió que, en casi dos décadas de gestiones ante el Estado y otros organismos, logren la consecución de los estudios técnicos, obtención de los recursos económicos que finalmente permitió iniciar la construcción de la infraestructura del sistema, mismo que hasta el 2019 las obras se encuentran paralizadas. Sin embargo, la organización en la etapa de ejecución del proyecto va disminuyendo su intensidad de participación y por último en la etapa de operación del sistema según el modelo de gestión, la participación de la organización en la toma de decisiones seguirá disminuyendo. Esta realidad en muchos usuarios del agua -miembros de la organización comunitaria- provoca que piensen y sientan que el proyecto es ajeno (de otros) a su realidad y prácticamente ya no es su proyecto.

La Constitución vigente reconoce dos formas de gestión del agua en el Ecuador: la pública y comunitaria; también deja abierta la posibilidad de realizar alianzas públicas-comunitarias. El modelo de gestión acordado para el PPI es la pública, para lo cual se crea una empresa que tendrá participación comunitaria; mientras que las JAAP y GAD Municipales pueden realizar alianzas público-comunitarios en cada cantón. ¿Qué significa esto? ¿Cuáles son los retos que esperan en adelante a los usuarios y comunidades en torno a sus JAAP y el PPI? 